\title{
Wat eene moeder lijden kan door Hendrik Conscience in het Pools. Vertaling of adaptatie?
}

\begin{abstract}
In this article the author discusses the Polish translation of Wat eene moeder lijden kan (What a mother has to suffer) by Hendrik Conscience, published in 1856. Due to a series of changes in the Polish translation the Polish text became different from its original. The question is how important those differences are and if they have a significant influence on the meaning of the text. The author's assumption is that the Polish translator Franciszek Salezy Dmochowski tried to adjust the text to local, Polish circumstances, according to ideas about translation which were widespread in the $19^{\text {th }}$ century. As a result, the process of 'localization' played a major role in the creation of Cierpienia matki, the Polish translation of Wat eene moeder lijden kan.
\end{abstract}

Keywords: Hendrik Conscience, cultural specific items, translation, Dutch literature

\section{Inleiding}

In 1843 publiceerde Hendrik Conscience een van zijn eerste zedenromans (of beter verhalen) onder de titel Wat eene moeder lijden kan. Hoewel het een kort stuk is, behoort het tot een van de meest vertaalde werken van Conscience. Het is onder andere in het Duits, Engels, Pools en Tsjechisch vertaald (Engelbrecht 2011: 88). Uit het meest recente onderzoek blijkt dat Conscience "[...] niet alleen de Vlaamse maar de hele moderne Nederlandstalige literatuur onder de aandacht van het buitenland heeft gebracht" (Humbeeck \& Absilis 2016: 14). Zijn werken waren vaak de eerste Nederlandstalige tekstendie in het buitenland zijn gepubliceerd. In sommige landen, zoals Tsjechië, had Consience een paar receptieperiodes (Engelbrecht 2016). Allereerst werd hij met de Vlaamse Beweging geassocieerd, daarna wordt hij als een katholiek getinte sociale auteur beschouwd en werd hij populair in Tsjechische katholieke kringen. Ten slotte wordt hij gezien als natonalistisch schrijver van De Leeuw van Vlaenderen (Engelbrecht 2016: 255-256). 
De Tsjechische vertaling van Wat eene moeder lijden kan is al in 1846 gepubliceerd als feuilleton in Česká wčela onder de letterlijk vertaalde titel Co matka snésti může. De Poolse versie van het verhaal kwam voor het eerst in 1856 uit als Cierpienia matki [Het lijden van de moeder] in het tijdschrift Rozrywki dla młodocianego wieku [Vermaak voor jongeren] in een vertaling van Franciszek Salezy Dmochowski (anoniem 1856). Jammer genoeg zijn in deze versie auteur en vertaler niet vermeld en is het verhaal als anonieme vertaling verschenen. Deze vertaling werd voor de tweede maal uitgegeven in een bundel van Consciences werken onder de titel Powieści belgijskie z życia rodzinnego [Belgische verhalen uit het gezinsleven], gepubliceerd in 1858 te Warschau. De vertaling begint met de voetnoot van de vertaler of uitgever waarin staat dat er in de vertaling wat wijzigingen zijn aangebracht: "Obraz ten zastosowałem, uczyniwszy w nim ledwie kilka zmian, do naszego kraju i scenę zamiast w Antwerpii, umieściłem w Warszawie [...]". (Conscience 1858: 321) [Dit tafereel heb ik, na enkele wijzigingen, naar ons land verplaatst en het plot heb ik, in plaats van Antwerpen, naar Warschau verplaatst]. In deze bijdrage wil ik nagaan welke aanpassingen door de vertaler zijn aangebracht en in hoeverre het oorspronkelijke verhaal intact is gebleven.

Dat het verhaal naar Warschau is verplaatst is heel typisch voor deze periode. Deze conclusie kan men trekken na het artikel van Wilken Engelbrecht (2013) die voorbeelden van Malý en Jungmann noemt als vertalers, die localisation hadden gebruikt bij vertalingen van Consciences werken naar het Tsjechisch. Beide vertalers hadden het plot van de oorspronkelijke verhalen naar Moravië verplaatst. De neiging om een verhaal te lokaliseren is verbonden met Belles Infidèles, een vertaaltendens uit de $17^{\mathrm{e}}$ eeuw in Frankrijk. Waar het belangrijkste doel was "[...] providing texts which may appeal to the French reader" en "adaptation was not seen as betrayal but rather as a means of adjusting the foreign work to suit contemporary tastes" (Salama-Carr 2001: 412-413). Dmochowski gebruikte het bovenstaande consequent.

Onderzoekers hebben wat werk gedaan om Poolse vertalingen van Consciences (Lipnicki 2013) te lokaliseren, maar tot nu toe zijn de vertalingen zelf niet uitvoerig besproken. Toch gaan onderzoekers er in hedendaags vertaalonderzoek van uit dat het noodzakelijk is om de vertalingen te analyseren. Zo stelt Pieter Boulogne (2013: 72):

Volgens mij is het voor een literatuurhistoricus niet enkel nuttig, maar noodzakelijk om bij het uitpluizen van een receptie behalve een licht te werpen op de literaire kritiek en de institutionele actoren ook aandacht te besteden aan wat er echt gerecipieerd werd - in het geval van een vertaalde schrijver zijn dat niet de originele teksten, maar de vertalingen. Al was het maar omdat de verschuivingen waardoor vertalingen gekenmerkt worden iets vertellen over de normen van de receptiegemeenschap, moet tenminste een poging ondernomen worden om enkele essentiële vertaalwetenschappelijke vragen te beantwoorden.

Het is dus noodzakelijk om een vertaalde tekst te analyseren, omdat zo nieuwe verschijnselen aan het licht komen. Door vertalingen te vergelijken met de 
brontekstkan men niet alleen 'fouten' ontdekken, maar vooral de meerwaarde van de vertaalde tekst. Zo kan een tekst vertaald zijn voor een specifiek doelpubliek en daarom aangepast zijn. ${ }^{1}$ Men kan hier denken aan adaptaties als jeugdliteratuur of hertalingen. Maar soms is de tekst op een andere manier bewerkt. In deze bijdrage wil ik nagaan in hoeverre de tekst van Wat eene moeder lijden kan in de Poolse vertaling is geadapteerd. Omdat de meeste verschillen cultuurspecifieke elementen betreffen, wil ik hier eerst iets zeggen over de methodologie.

\section{Cultuurspecifieke elementen}

Sommige onderzoekers, zoals Bassnet (2002), beschouwen een vertaling als een vorm van relatie die door diverse buitenlinguïstische factoren wordt gekenmerkt. Hervey en Higgins (1992) zijn van mening dat een vertaler de kloof tussen twee taalculturen dient in te vullen door het maken van culturele bruggen die communicatie tussen beide culturen mogelijk maken. Daarbij stuit men vaak op een probleem, als het gaat om cultuurspecifieke elementen. Deze vergen een specifieke vertaalstrategie. Grit (2010) gebruikt hiervoor de term realia die ook in deze bijdrage wordt gehanteerd. Volgens Grit (2010: 189) zijn realia "concrete unieke verschijnselen of categorale begrippen die specifiek zijn voor een bepaald land of cultuurgebied en die elders geen of hooguit een gedeeltelijk equivalent kennen en eveneens de voor deze verschijnselen/begrippen gebruikte termen". Onder de term 'vertaling' dient men in deze bijdrage een tekst te beschouwen "[...] die is omgezet in een andere taal dan waarin hij oorspronkelijk werd geschreven" (G.J. van Bork e.a. 2002: vertaling). Daarnaast kan men ook over 'adaptatie' spreken. Hieronder dient men te verstaan een "aanpassing of bewerking van een literair werk om het geschikt te maken voor een ander medium en/of ander publiek dan waarvoor het oorspronkelijk bedoeld is" (G.J. van Bork e.a. 2002: adaptatie).

De tekst van Grit werd voor het eerst in 1997 gepubliceerd en correspondeertmet het werk van Aixelá (1996). Volgens hem moet men culture-specific items (hierna CSI) als volgt definiëren.

Those textually actualized items whose function and connotations in a source text involve a translation problem in their transference to a target text, whenever this problem is a product of the nonexistence of the referred item or of its different intertextual status in the cultural system of the readers of the target text (Aixelá 1996: 58).

Beide definities liggen dicht bij elkaar. Aixelá voegt daarbij nog de connotaties in de brontekst. Beide auteurs maken gebruik van verschillende termen om bepaalde typen van vertaalstrategieën te benoemen. Voor de vergelijking van de brontekst

${ }^{1}$ Een voorbeeld daarvan is de Poolse editie van Max Havelaar uit 1950. Deze versie is een literaire bewerking van een vooroorlogse vertaling van Multatuli's werk als toneelstuk voor een jeugdig publiek (Mutaltuli 1950). 
Wat eene moeder lijden kan met de doeltekst Cierpienia matki maak ik gebruik van beide aanpakken. Eerst zal de plot van het oorspronkelijke verhaal worden besproken, omdat de Poolse vertaler wat wijzigingen in de tekst heeft aangebracht.

\section{Plot van Wat eene moeder lyden kan}

De plot van Wat eene moeder lyden kan lijkt eenvoudig te zijn. Op een vrijdag in januari 1841 bezoeken twee jonge dames uit de 'hogere klasse' arme werklieden van Antwerpen. Ze geven aalmoezen aan de armen en spreken over de aard van bedelaars. De eerste vrouw, Adela, is van mening dat indirecte hulp, bijv. door inschrijving voor een bepaald bedrag dat regelmatig betaald moet worden, beter is dan "[...] zelve in al die vuile wooningen te gaen" (Conscience 1857: 6). Haar vriendin Annah is een andere mening toegedaan. Voor haar betekent weldadigheid vooral directe hulp aan mensen in nood. Ze geeft wel toe dat er mensen bestaan, die het bedelen als een soort ambacht zien en het gebruiken om ervan te leven. Maar er zijn ook talloze armen die helemaal niet klagen over hun lot en hun best doen om te werken. Annah overtuigt Adela om met haar mee te gaan:

Kom met my, ik zal $\mathrm{u}$ werklieden toonen wier kleederen niet gescheurd zyn, wier huishouden niet vuil is, en wier mond zich niet zal openen om te vragen, maer alleen om te danken en te zegenen. Gy zult den afgryselyken honger op hunne wezenstrekken geschilderd zien, - het zwarte brood bevrozen tusschen de verstevene vingeren der kinderen, de tranen der moeder, de sombere wanhoop des vaders... Ho! sloegt gy uw oog op dit stomme tafereel van smart en lyden, wat engelen blydschap zoudt gy vinden in dit alles met een weinig gelds te veranderen. - Gy zoudt die arme kinderen zich dansend aen uwe kleederen zien hechten; de moeder met saemgevoegde handen u toelachen; den vader, door dankbaerheid verdwaeld, uwe fyne hand in zynebeenige handen drukken en ze met brandende tranen besprengen! - En dan, daar zoudt gy ook tranen van zaligheid storten, Adela, en gy zoudt uwe handen aen de hunnen, hoe ruw ook, niet onttrekken (Conscience 1857: 6-7).

De woorden van Annah worden niet alleen gebruikt om Adela te overtuigen. Ze vormen tevens een korte samenvatting van het verhaal zelf. Met deze techniek wilde de auteur een verwachting oproepen. De lezer weet precies wat er gaat gebeuren: de twee vrouwen gaan woningen van armen bezoeken en ze zullen vast en zeker arme mensen tegenkomen die hun hulp nodig hebben.

En dat gebeurt inderdaad. In een huis, waar de vrouwen vlakbij staan, woont een arm gezin. De woning is onplezierig en niet echt geschikt om te wonen:

De lucht was er zoo koud als op de straet, en eene zekere vochtigheid drong er door de kleederen van hen die er zich bevonden; in den haerd brandde een klein vuer, dat met stukken van gebrokene meubelen gevoed werd, en, als met moeite, van tyd tot tyd eenige schaersche vlammen vertoonde (Conscience 1875: 7-8).

Vanaf het begin ziet de lezer het gebrek aan materieel eigendom bij de bewoners. In het huis is het heel koud, omdat de inwoners geen geld hebben om goed 
brandhout of kolen te kunnen kopen. Ze moeten dus ongewild hun eigen huisraad vernietigen. Later komt de lezer te weten dat de moeder een stoel gebruikte om haar zieke kindje wat warmte te geven. De moeder Trees en de twee kinderen, het jongetje Janneken en het meisje Mieken, zijn aan het wachten. Ze wachten op de vader die is gaan werken. Mieke is ziek en ligt in bed. Het gezin is te arm om hulp van een arts te vragen. De moeder is bang dat haar één jaar oude dochtertje binnenkort sterft. De vader komt binnen na een ellendige hongerscène van Janneken die het laatste stukje brood wil opeten, omdat hij zoveel honger heeft. Sus is een arbeider die met een mosselbak bij het spoor werkt. Hij heeft geen geluk gehad en niets verdiend. Omdat hij te trots is om te gaan bedelen, neemt hij zijn mosselbak en gaat hij naar de vrijdagmarkt om hem te verkopen. Hij hoopt na de verkoop nog wat werk te kunnen vinden voordat het geld van de mosselbak op is.

De twee vrouwen komen op de markt en ze luisteren toevallig het gesprek van Sus en zijn vriend af. De verdrietige arbeider beschrijft zijn ellende. De weldadige vrouwen kopen zijn mosselbak voor zevenentwintig frank. Ze kopen nog wat aardappelen, brood en hout bij een naburige winkel en gaan met Sus naar de Winkelstraat, waar hij woont. De man heeft er geen idee van dat de vrouwen dit alles voor zijn gezin hebben gekocht. Als ze thuiskomen, zien ze dat Trees is flauwgevallen. Annah geeft Sus wat geld om wat wijn te kopen en ze perst het sap van een sinaasappel in de mond van de vrouw. Tegelijkertijd geeft Adela een stukje brood aan Jannetje en zoals beloofd aan het begin van het verhaal begint ze te huilen:

Janneken vatte den boterham met blydschap, kuste zyne hand ten teeken van dankbaerheid, en aenzag Adela met zulke zoete blikken, dat ze zich omwenden moest om hare tranen van aendoening te verbergen (Conscience 1857: 18).

$\mathrm{Na}$ een ogenblik komt Trees weer tot bewustzijn. Annah geeft wat geld aan het gezin en zegt dat de mosselbak nog van Sus is. De familie is blij. Ze bedanken zegenende twee vrouwen. Deze gaan weg. Adela begrijpt nu wat Annah met haar woorden bedoelde.

De lezer kan denken dat het verhaal een goede afloop heeft. Iedereen is gelukkig, maar er wordt met geen woord meer over de zieke Mieken gesproken. De lezer weet niet of het meisje nog leeft. De twee vrouwen gedragen zich alsof ze alleen Trees en haar zoontje zien. De verteller zwijgt ook over het lot van het kind. We kunnen dus aannemen dat het meisje is overleden en dat haar dood de oorzaak van het flauwvallen van Trees is geweest.

\section{Analyse van de Poolse vertaling}

Om de vertaalde tekst passend te analyseren, moeten allereerst enkele veranderingen worden vermeld. Laten we beginnen om die per categorie op te sommen. 


\subsection{Geografische realia}

Zoals reeds vermeld is het verhaal van Cierpienia matki verplaatst naar Polen en wel naar Warschau. De oorspronkelijke toponiemen zijn vervangen door Poolse namen. Volgens Aixelá (1996: 63) gaat het hier om naturalisation. Grit (2010: 192) spreekt van adaptatie. Omdat de vertaler het verhaal naar Polen verplaatste, moest hij ook de lokale toponiemen aanpassen. ${ }^{2}$ Daarom zijn Antwerpse straat- en plaatsnamen veranderd in hun Poolse microtoponiemen. Zo is de Winkelstraat in het Pools de ulica Freta [Fretastraat] geworden.

Sommige toponiemen zijn zelfs weggelaten. Bij de beschrijving van Mieken vertelt de schrijver dat "[...] eene plaets Stuivenberg het onnoozel wicht weldra zou ontvangen" (Conscience 1857: 8). In de voetnoot stelt de auteur de lezer ervan op de hoogte dat Stuivenberg een "Begraefplaetsby Antwerpen" is. De Poolse vertaler vond daarvoor geen goede oplossing en schrijft "[...] to biedne stworzenie wkrótce zamrze" (Conscience 1858: 269) [dit onnozel schepsel gaat binnenkort sterven]. Hier is er dus sprake van weglating (Grit) of deletion (Aixelá) in de doeltekst. De Poolse lezer krijgt dus geen informatie over het kerkhof en wordt meer rechtstreeks betrokken bij de slechte toestand van het meisje.

Het verplaatsen van het plot naar Warschau heeft ook andere gevolgen voor de toponymie van het verhaal. Sus gaat zijn eigendom op de Vrijdagmarkt vlakbij Valkenstraetje verkopen (Conscience 1857: 12). De Vrijdagmarkt was en is in de meeste Vlaamse steden (en zo ook te Antwerpen) de typische rommelmarkt en dus de geëigende plek voor arme mensen om hun laatste goederen te gelde te maken. De Poolse Franciszek probeert zijn waar op een stoep op de Rynek Starego Miasta [Markt van de Oude Stad] voor een kruidenwinkel tegenover de ulica Piwna [Bierstraat] te slijten. ${ }^{3}$ In de Poolse vertaling gaat de verkoop wel heel anders te werk, omdat het Vlaamse systeem van een roeper die voor vendumeester speelt, in Polen op rommelmarkten onbekend is. Hier wordt de prijs van de waar gewoon tussen koper en verkoper afgesproken.

\subsection{Persoonsnamen}

Bij de persoonsnamen heeft Dmochowski ook interessante keuzes gemaakt. Je zou kunnen verwachten dat hij de persoonsnamen van personages zou behouden (handhaving volgens Grit of repetition volgens Aixelá). Hij heeft dat inderdaad gedaan, maar heeft daarbij de Poolse naam daarvoor gebruikt (ortographic adaptation volgens Aixelá). De Poolse lezer heeft dus te maken met Anna, Teressa

${ }^{2}$ Ook vertalingen van Het Goudland van Conscience zijn aan adaptatie onderworpen. Boyden en Vanderbussche (2012) gebruiken daarvoor de term domestication (vgl. Venuti 1995: 20).

${ }^{3}$ Deze plaats heet tegenwoordig Zapieciek en was tot voor de Tweede Wereldoorlog ook een geliefde plek voor rommelmarkten. 
(Trees), Franciszek (i.p.v. Sus = Franciscus), Jaś (Janneken), Marysia $($ Mieken). De vertaler is overigens niet helemaal consequent in zijn vertaalstrategie. Hij vertaalt de voornaam van Geert (een vriend van Sus) als Grzegorz (Gregorius of Joris). Hij weet wellicht niet dat Geert overeenkomt met het Poolse Jerzy. Maar in één geval toont de tekst zelf dat de vertaler opzettelijk namen heeft aangepast, omdat hij waarschijnlijk met een vertaalde versie van de brontekst werkte, dus met een tussentaal. Dmochowski kende goed Frans en Engels. In zijn vertaaloeuvre vindt men Scott, Molière, Voltaire en Balzac. Hij heeft mogelijk voor zijn vertaling een Franse vertaling van Consciences verhaal gebruikt. ${ }^{4}$ Waarschijnlijk gaat het om de in 1852 in Doornik gepubliceerde vertaling Ce qu'unemère peut souffrir: histoire véritable vertaald door E. Oliver (Arents 1931: 45). Maar Dmochowski heeft zijn tekst niet goed nagelezen, want er is wel een fout opgetreden bij de vertaling van één voornaam, Adela. De Poolse lezer heeft te maken met een Bronisława. De voornaam Adela komt maar eenmaal voor, als beide vriendinnen elkaar begroeten: (Conscience 1858: 322-323):

- Dzień dobry ci Bronisławo, jak się masz?

- Zdrowa jestem, a ty?

- I ja także, i więcej jestem z siebie samej zadowolona, niżeli ci wypowiedzieć zdołam.

- A to dlaczego? Mamy czas taki mroźny i nie mily.

- Dla mnie jest bardzo miły. Dopiero od godziny wyszłam z domu, a już zwiedziłam kilkanaście rodzin ubogich. Widziałam nędzę, kochana Adelo, taką nędzę, co aż się serce kraje. [...]

- Cóż to? Chcesz płakać Anno? [mijn accentuering, M.L.]

De Poolse vertaling komt met de oorspronkelijke tekst redelijk overeen (Conscience 1857: 6):

« Goeden dag, Adela. Hoe gaet het? »

«Tamelyk wel, en met u?»

« God zy dank, ik ben gezond en zoo verheugd dat ik het u niet zeggen kan.»

« Waerom? Het schyntmy dat het weder zoo vermakelyk niet is?»

« Ja, voor my wel, Adela. Ik ben nog maer een uer uit het bed, en reeds heb ik twintig arme wooningen bezocht. Maer ik heb armoede gezien, lieve Adela, armoede dat het hart ervan breken zou.[...]»

« Men zou zeggen dat gy goesting hebt om te weenen, Annah! [...]» [mijn accentuering, M.L.]

Dmochowski veranderde dus de voornaam Adela in Bronistawa, maar is op één plek vergeten deze te corrigeren. Waarschijnlijk vond Dmochowski's de westerse voornaam Adela te ongewoon voor Poolse lezers. Daarom gebruikte hij een toen heel typische Poolse voornaam.

In zijn vertaling voerde hij ook een nieuw personage in. Dat is een Jood. Zijn naam is Hersz Saltzman en hij koopt het bezit van Franciszek. Dmochowski heeft de Jood geïntroduceerd om de toenmalige realia van Polen te benadrukken. Voor

${ }^{4}$ Uit Marrécau 1975: 25 blijkt dat er Franse vertalingen van Wat eene moder lyden kan bestonden. 
de Tweede Wereldoorlog was de Joodse gemeenschap de sociale groep, die zich in Warschau het meest met straathandel bezighield. Dmochowski gebruikte stereotypen om het gedrag van de Jood te beschrijven. De Jood deed een oneerlijk bod op het bezit van Franciszek (anders dan bij Conscience verkocht Franciszek zijn jas en twee strijkijzers, omdat hij in de Poolse versie een kleermaker is). De Jood kocht zijn jas onder de marktprijs. Volgens Franciszek was zijn jas tenminste vier roebel waard en de Jood betaalde er slechts anderhalve roebel voor. Een andere Jood betaalde twee zloty voor beide strijkijzers van Franciszek. De arme kleermaker was zeer kwaad over de prijs en reageerde zeer emotioneel (Conscience 1858: 335-336):

- Daj i idź do wszystkich diabłów! zawołał zniecierpliwiony krawiec. Ten surdut wart najmniej cztery ruble.

- „No, po co ja mam iść do wszystkich diabłów? co mi z tego przyjdzie? czy ja tam co kupię? ["Geef het [geld] en loop naar de duivel!" riep de kleermaker ongeduldig. "Deze geklede jas is tenminste vier roebel waard". "Nou, waarom zal ik naar de duivel moeten lopen? Wat heb ik daaraan? Kan ik daar iets kopen?']

De Joodse koopman wordt met de toenmalige stereotypen uitsluitend negatief afgeschilderd. Hij wil vooral winst behalen en niet helpen. In de oorsponkelijke tekst zijn er geen Joden vermeld. Hier kunnen we met Aixelá over autonomous creation spreken. De vertaler trachtte daarmee consequent het verhaal zo toegankelijk mogelijk voor zijn Poolse doelpubliek te maken.

De inbreng van de Joden door de vertaler met al die negatieve stereotypen kan van antisemitisme getuigen. Dmochowski is door zijn vader, Franciszek Ksawery Dmochowski, voormalige priarist, en door Antoni Jakubowicz (de leraar van jonge Dmochowski) conservatief opgevoed (Dmochowski 1858: 16-20). Hij ging vooral naar scholen van de paters Piaristen waar de leraren streng waren en lijfstraffen gebruikten. Hij was pas 7 jaar oud toen zijn vader overleefd in 1808 . Wegens zijn vaders schulden en politieke situatie in Polen was familie Dmochowski gedwongen on hun huis te Warschau te verkopen. Dmochowski ervoer meermaals armoede en had tot 1830 bijna altijd financiële problemen (hij was zelfs gedwongen om in 1822 zijn familiedorp te verkopen), die door zijn schrijf- en uitgeversactiviteiten werden opgelost (hij richtte twee boekhandels in Warschau op waar hij zijn vertalingen verkochte). Dat kan zijn radicale verhouding tegen de Joden, de toenmalige sociale laag die met rijkdom was geassocieerd, verklaren.

\subsection{Naturalisation van de realia}

Als vertaler besloot Dmochowski om het verhaal van Conscience te wijzigen. Dat betrof vooral CSI die voor de Poolse lezer in beginsel niet duidelijk genoeg waren. Dmochowski werkte regelmatig met adaptatie om een gewenst effect bij de Poolse lezer te krijgen. Daarom verplaatste hij het arme gezin van een huis naar een zolderwoning. In zijn tijd waren deze woningen in Polen het 
goedkoopste en daar woonden toen de armen. Daarnaast kleedde hij Bronisława en Anna in mooie kleren die typisch waren voor de Poolse adel. De vrouwen komen elkaar in zijn versie tegen voor de Dominicanenkerk, op de ulica Freta vlak buiten de Oude Stad en niet in de wijk der armen. Deze keuze is het gevolg van het toepassen van de naam ulica Freta. Ik vind die plek op zich wel goed gekozen. De Fretastraat was een gegoede winkelstraat en de Domicanenkerk is het laatste grote gebouw van de Fretastraat voordat men de stadspoort doorgaat richting Rynek.

Ook zal een mosselbak iets onduidelijks voor Polen zijn, omdat mosselen niet typisch voor de Poolse cultuur waren. Dmochowski heeft een ander beroep voor de arme werkman gekozen, hij is namelijk een kleermaker. De ambachtsman moest zijn uitrusting verkopen om eten en hout voor zijn familie te kunnen kopen. Daardoor was hij gedwongen om zijn werkgereedschap te verkopen en daardoor zou hij geen werk meer kunnen verrichten.

In de oorspronkelijke tekst, toen Trees van honger was flauwgevallen, begint Anna haar met een sinaasappel aan te sterken. In de Poolse versie is dat op een heel andere manier gedaan. "Wyjęła z woreczka flakonik z wódką kolońską i rozcierała nią pulsa zemdlonej" (Conscience 1857: 339) [Ze haalde een flesje Keuls water uit een zakje en begon de polsen van de flauwgevallene in te wrijven]. Het flesje Keuls water of Eau de Cologne, die door oudere dames graag werd en wordt gebruikt om flauwtes te bestrijden, was volgens Dmochowski voor de Poolse lezer in januari 1841 logischer dan een verse sinaasappel.

Dmochowski ging nog een stap verder in zijn aanpassingen. Hij veranderde het slot van het verhaal. Zoals eerder vermeld verzweeg Conscience het verdere lot van Mieken. De lezer is niet zeker of het meisje nog leeft. In de Poolse vertaling leest men dat Anna een bepaald bedrag aan het gezin gaf en aan Franciszek vroeg om de volgende dag bij haar te komen. Ze gaf hem haar adres en zou hem waarschijnlijk wat werk kunnen geven. Verder riep Anna een arts die binnen een half uur zou komen. De Poolse lezer kreeg dus het beeld dat alles met de arme familie in orde zou komen. Het dubbelzinnige einde van Conscience is niet behouden.

\section{Conclusie}

De Poolse vertaling van Wat eene moeder lijden kan zal volgens de hedendaagse vertaalcriteria niet als een 'mooie' vertaling beschouwd mogen worden. Er zijn heel veel nieuwe elementen door de Poolse vertaler toegevoegd en veel zaken zijn aangepast. Franciszek Salezy Dmochowski gebruikte vooral naturalisation (of localisation) als een van zijn belangrijkste vertaaltechnieken. Daarom krijgt men de indruk dat het verhaal ver van het origineel ligt. Maar het past bij de toenmalige vertalingsmethodes, die in heel Europa bekend waren. 
Aan de andere kant zijn cruciale elementen van de plot hetzelfde gebleven. Uit bovenstaande analyse blijkt dat zijn vertaling een eigen schrijfimpressie is, die hoogstwaarschijnlijk door zijn persoonlijke ervaringen is gemotiveerd. Door zijn aanpassingen heeft de Poolse lezer een gemodificeerde versie van het Conscience verhaal gekregen. Of dat slecht of goed voor de Vlaamse schrijver is laat ik buiten mijn beschouwing.

De door Dmochowski genaturaliseerde tekst is zo toegankelijk mogelijk voor de Poolse lezer gemaakt. Als ervaren uitgever en vertaler wist Dmochowski wat er op de Poolse markt rendabel zou zijn en wat er nodig was. Hij wilde dat zijn versie van het verhaal bij de lezer in de smaak viel en daarom maakte hij zo veel aanpassingen.

De Poolse Neerlandica Katarzyna Tryczyńska heeft in 2015 een waardevolle opmerking over CSI gemaakt. In haar bijdrage is zij van mening dat:

De cultuurspecifieke elementen van een tekst kunnen onbelangrijke details lijken, maar, zoals gezegd, is juist daar de couleur locale van het origineel vaak te vinden. Het zijn details die we als de specerijen kunnen beschouwen, waarmee de vertaler in zijn/haar vertalerskeuken verstandig en vakkundig, soms op het gevoel, moet omgaan (Tryczyńska 2016).

Als men haar vergelijking wil volgen dan kan er gezegd worden dat de Poolse vertaling van Wat eene moeder lijden kan op een tomatensoep lijkt die met andere specerijen is gekruid dan het origineel. De soep blijft wel hetzelfde, maar smaakt overal anders.

\section{Bibliografie}

[anoniem] (1856): “Cierpienia matki”. In: Duchińska, Seweryna (ed.): Rozrywki dla młodocianego wieku: dzieło zbiorowe w 4-ch tomach obejmujace powieści, poezye, podróze, literaturę i rozmaitości, Vol. 4. Warszawa: M. Glücksberg, 266-284.

Arents, Prosper (1931): Flemish Writers Translated (1830-1931). The Hague: Martinus Nijhoff.

Aixelá, Javier F. (1996): “Culture-specific Items in Translation”. In: Rodriguez, Román Alvarez \& Vidal, Carmen Africa (ed.): Translation, Power, Subversion. Clevedon/Philadelphia/Adelaide: Multilingual Matters, 52-78.

Bassnett, Susan (2002): Translation Studies. London: Psychology Press.

Bork, G.J. van e.a. (2002): Letterkundig lexicon voor de neerlandistiek. Laatst geraadpleegd op 10.10.2016 (http://www.dbnl.org/tekst/bork001lett01_01/bork001lett01_01_0023.php).

Boulogne, Pieter (2013): "Nietes-welles. Waarom vertaalwetenschap wel cruciaal is voor de Receptiewetenschap". In: Filter, Tijdschrift over Vertalen 20: 66-72.

Boyden, Michael \& Vandenbussche, Liselotte (2012): "Translating the American West into English: The case of Hendrik Conscience's Het Goudland". In: Western American Literature 47, 1: 23-44.

Conscience, Hendrik (1857): Wat eene moeder lyden kan. Een ware geschiedenis. Antwerpen: J.P. Van Dieren.

Conscience, Henryk (1858): “Cierpienia matki”. In: Conscience, Henryk: Powieści belgijske z życia rodzinnego (vertaling Franciszek S. Dmochowski), Vol. 1. Warszawa: Hindemith, 321-344. 
Dmochowski, Franciszek Salezy (1858): Wspomnienia od 1806 do 1830 roku. Warszawa.

Engelbrecht, Wilken (2011): "Hendrik Conscience, de man die de Tsjechen Nederlandse literatuur leerde lezen”. In: Hrnčiřová, Zdenka e.a. (ed.): Praagse Perspectieven 7. Handeling van het colloquium van de sectie Nederlands van de Kareluniversiteit te Praag op donderdag 24 en vrijdag 25 maart 2011. Praha: Univerzita Karlova, 83-105.

Engelbrecht, Wilken (2013): “A Moravian picture of Dutch literature”. In: Zehnalová, Jitka, Molnár, Ondřej \& Kubánek, Michal (ed.): Tradition and Trends in Trans-Language Communication. Olomouc: Palacký University, 215-228.

Engelbrecht, Wilken (2016): "De Tsjechische Conscience". In: Humbeeck, Kris e.a. (ed.): De Grote Onleesbare. Hendrik Conscience herdacht. Gent: Academia Press, 239-263.

Grit, Diederik (2010): “De vertaling van realia!”. In: Naaijkens, Ton e.a. (ed.): Denken over vertalen. Tekstboekvertaalwetenschap. Nijmegen: Vantilt, 189-196.

Hervey, Sándor G.J. \& Higgins, Ian (1992): Thinking Translation: A Course in Translation Method. New York: Routledge.

Humbeeck, Kris \& Absillis, Kevin (2016): "De man wiens volk hem niet meer wil lezen”. In: Humbeeck, Kris e.a. (ed.): De Grote Onleesbare. Hendrik Conscience herdacht. Gent: Academia Press, 5-111.

Lipnicki, Marcin (2013): “'De leeuw zonder klauwen’. Een paar opmerkingen over vertalingen van Hendrik Conscience in het Pools tijdens de tweede helft negentiende en begin twintigste eeuw". In: Engelbrecht, Wilken \& Waterlot, Muriel (ed.): De Lage Landen - The Low Countries. Handelingen van het Colloquium gehouden op 8 en 9 mei 2012 bij de Johannes Paulus II Katholieke Universiteit Lublin. Lublin: Wydawnictwo KUL, 55-64.

Marrécau, Philippe (1975): La diffusion des oeuvres d'Henri Conscience en France. Leuven: KU Leuven (onuitgegeven licentiaatsverhandeling).

Mutaltuli (1950): Maks Havelaar. Adaptacja sceniczna Anny Milskiej (vertaling Bronisława Neufeldówna, bewerkt door Anna Milska). Warszawa: Książka i Wiedza.

Salama-Carr, Myriam (2001): "French tradition". In: Baker, Mona (ed.): Routledge Encyclopedia of Translation Studies. London: Routledge, 407-419.

Tryczyńska, Katarzyna (2015): "Wat heeft bigos met snoekbaars in mayonaise te maken? Enkele impressies over cultuurspecifieke elementen". In: Filter. Tijdschrift over vertalen, laatst geraadpleegd op 10.10.2016 (http://www.tijdschrift-filter.nl/webfilter/vrijdag-vertaaldag/2015/week50-katarzyna-tryczynska.aspx).

Venuti, Lawrence (1995): The Translator's Invisbility: A History of Translation. London/New York: Routledge.

Marcin Lipnicki $\left({ }^{*} 1987\right)$ is promovendus bij de Vakgroep Nederlands van de Johannes Paules II Katholieke Universiteit te Lublin, waar hij Nederlands en Pools gestudeerd heeft. Hij is tevens medewerker bij de vakgroep Nederlands. Zijn interesse gaat uit naar de receptie van Poolse werken in Nederland en de receptie van Nederlandse literatuur in het Pools. Zijn dissertatie gaat over vertalingen van het werk van Kraszewski in het Nederlands.

e-mail: marcin.lipnicki.m@kul.lublin.pl 